\title{
Primitive Bilateral Ocular Melanoma in a Black Patient
}

\author{
Essossinam Kpelao1, Nidain Maneh2 ${ }^{*}$, Harrefegena Bissa3, Koffi Amegbor ${ }^{4}$, \\ Kadanga Anthony Beketi ${ }^{1}$, Abdel Kader Moumouni', Agbeko Doleagbenou ${ }^{1}$, \\ Thierry Alihounou ${ }^{5}$, Julienne Noudé Teclessou6, Komi Patrice Balo
}

\author{
${ }^{1}$ Department of Neurosurgery, University of Lome, Lome, Togo \\ ${ }^{2}$ Department of Ophthalmology, University of Lome, Lome, Togo \\ ${ }^{3}$ Department of Maxillofacial Surgery and Stomatology, University of Lome, Lome, Togo \\ ${ }^{4}$ Department of Pathology, University of Lome, Lome, Togo \\ ${ }^{5}$ Department of Surgery, Oueme and Plateau Teaching Hospital, Porto-Novo, Benin \\ ${ }^{6}$ Department of Dermatology, University of Lome, Lome, Togo \\ Email: *manehnid@hotmail.fr
}

How to cite this paper: Kpelao, E., Maneh, N., Bissa, H., Amegbor, K., Beketi, K.A., Moumouni, A.K., Doleagbenou, A., Alihounou, T., Teclessou, J.N. and Balo, K.P. (2017) Primitive Bilateral Ocular Melanoma in a Black Patient. Open Journal of Ophthalmology, 7, 256-261.

https://doi.org/10.4236/ojoph.2017.74034

Received: August 19, 2017

Accepted: October 9, 2017

Published: October 12, 2017

Copyright $\odot 2017$ by authors and Scientific Research Publishing Inc. This work is licensed under the Creative Commons Attribution International License (CC BY 4.0).

http://creativecommons.org/licenses/by/4.0/

\begin{abstract}
Introduction: Ocular melanoma develops at the expense of eyes' melanocytes which give to the eyes their color. It is the first primitive intraocular tumor in the White race. It is rare, as that of the skin in black people. The bilateral cases are exceptional even in the white race, estimated at $0.2 \%$. We present the case of bilateral ocular melanoma with bad prognosis in a black patient. Patient and observation: A 56-year-old black male patient, who had benefited 4 years earlier from an enucleation of the right eye for ocular melanoma, and admitted for bilateral exophthalmos which evolved for three months in a context of bilateral blindness. The cerebral Scanning had allowed to objectify a bilateral lateral-conical mass which evoked an inflammatory pseudo tumor. The failure of the medical treatment led to the exeresis of a conical, juxta-orbital and mid-muscular blackish mass, to the later apex respecting the surrounding structures. The histological examination ends again in a melanoma. No additional therapy was undertaken. The evolution 2 years later was marked by a local recurrence, multiple hepatic metastases and patient death. Conclusion: Bilateral ocular melanoma is exceptional in Black people. The etiologic factors as well as bilateralism mechanisms are still hypothetic. Its most effective treatment is local and the prognosis, bad in case of metastases due to the absence of an effective chemotherapy.
\end{abstract}

\section{Keywords}

Bilateral, Ocular Melanoma, Black Patient 


\section{Introduction}

Ocular melanoma develops at the expense of eyes' melanocytes which give to the eyes their color. This tumor can come from one of the four structures of the eyes: uvea, conjunctiva, eyelid and orbit. Of all these structures, uveal melanoma is the most frequent and represents about $5 \%$ of all the melanomas of the body [1]. It is the first primitive intraocular tumor in the White race [2]. It is rare, as that of the skin in Black people and does not exceed $1 \%$ of all the intraocular melanomas all races included according to the available publications [3] [4]. The bilateral cases are exceptional even in the white race, estimated at $0.2 \%$ and probably involve a predisposition or a genetic mutation in their pathogenesis [5].

We are reporting a case of primitive bilateral ocular melanoma in a Black subject. From this case, we shall discuss the epidemiology, the etiopathogeny and the prognosis of this pathology through a literature review.

\section{Patient and Observation}

It was a 56-year-old black male patient, admitted for a bilateral exophthalmos which had been developing for three months in a context of bilateral blindness. The clinical history went 4 years back, with a progressive decrease of the visual acuity of the right eye. The ophthalmologic examination of the right eye had shown an inflexible exophthalmos, a hypopyon with an absence of perception of light. The left eye was clinically normal with an acuity of 10/10. An enucleation of the right eye with the installation of ocular prosthesis had been realized. The histological examination of the part had concluded an ocular melanoma.

After a period of 4 years of clinical stability, headaches appeared gradually, a reduction in the visual acuity of the left eye quickly leading to blindness after 3 months in a context of painful bilateral exophthalmos. The cerebral scanning had enabled to objectify a side mass repulsing the prosthesis at the level of the right eye and a lateral-conical mass on the left, responsible for a left exophthalmos which made evoke an inflammatory pseudotumor a priori (Figure 1).

The failure of the medical treatment associated with a progress of the local symptomatology had indicated a surgery. This surgery enabled the total exeresis on the left altogether with a conical, juxta-orbital and mid-muscular blackish mass, to posterior apex respecting the surrounding structures of which the implantation basis was scleral (Figure 2) and on the right a blackish mass occupying the entire orbit. The histological examination ends again in a melanoma (Figure 3). The initial results of the extension did not objectify metastases. We proposed to the patient an evisceration on the right side and an enucleation of the left eye to realize a cancer exeresis but this proposal was refused.

The evolution 2 years later was marked by a local recurrence and hepatic metastases and patient death.

\section{Discussion}

Ocular melanoma comes from the degeneration of melanocytes located in the 


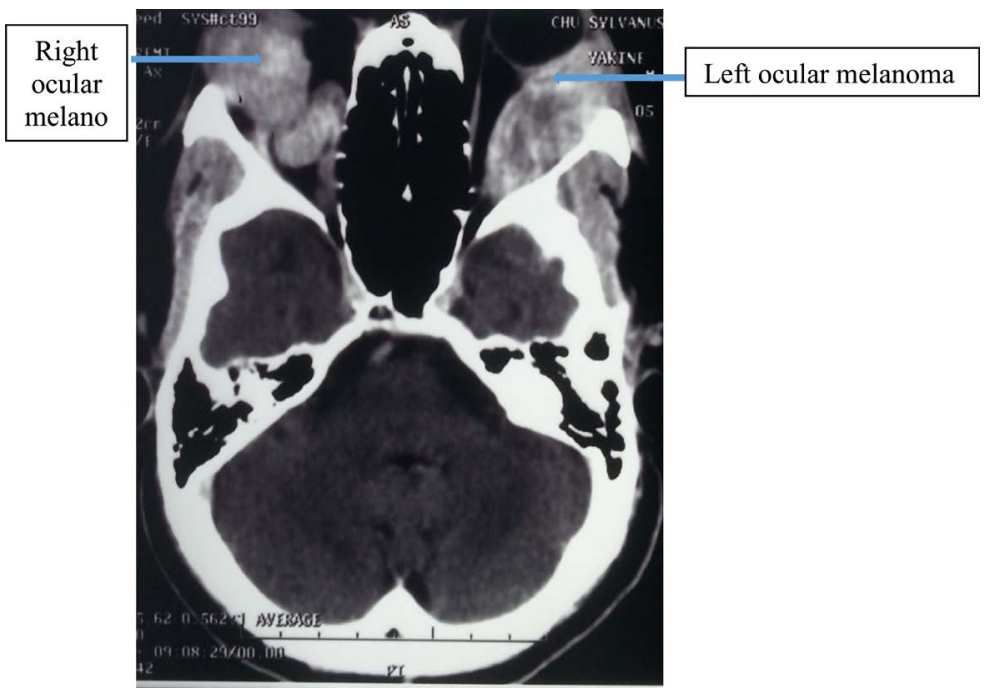

Figure 1. CT scan of the tumor in coronal reconstruction.

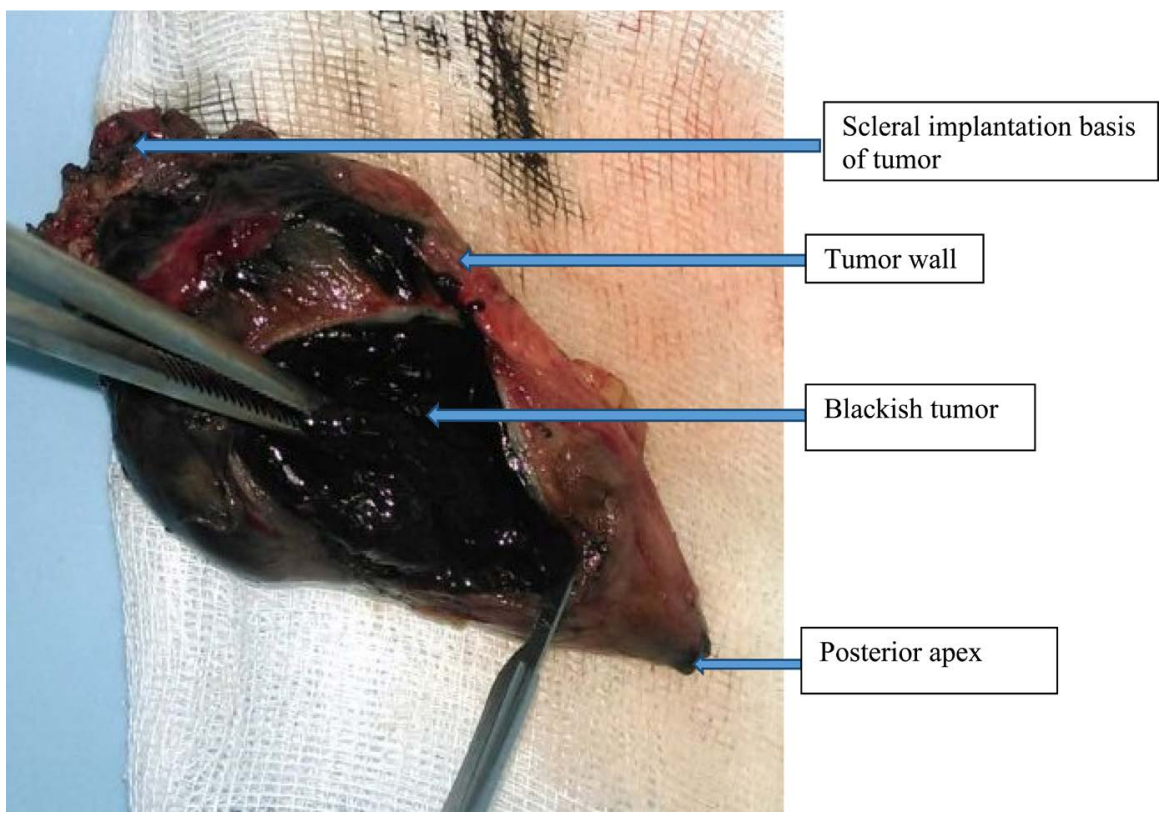

Figure 2. Macroscopic appearance of the surgical specimen (left eye).

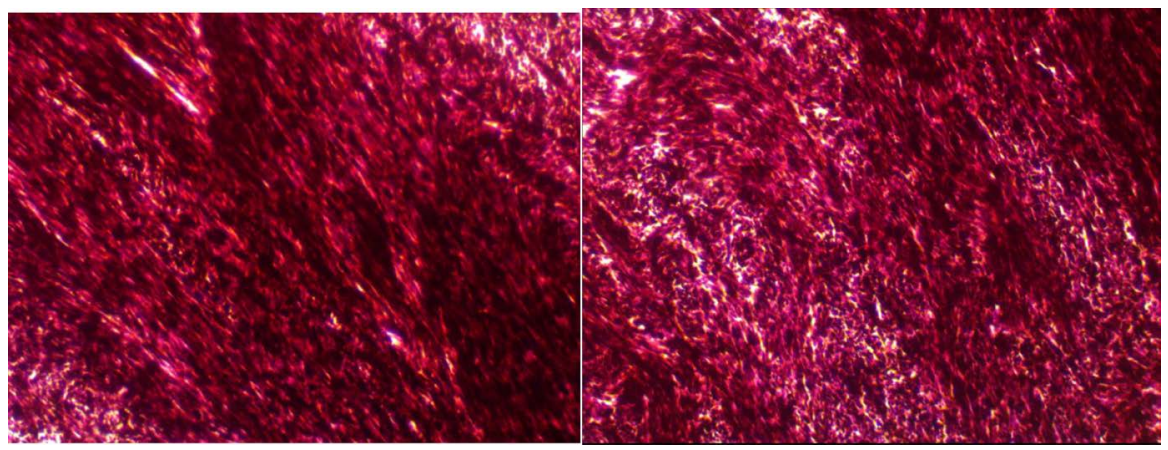

Figure 3. Histological appearance of the surgical specimen (left eye), demonstrating a round or polygonal cells with sometimes smoky cytoplasm and large nuclei (Malignant proliferation). 
eyes. These cells are located in all the constituents of the eyes but mainly at the level of the uvea. Situated in the deep layers of the uvea, melanocytes produce pigmented granules rich in melanin, called melanosomes which contribute to the constitution of the "darkroom" of the eyes and protect them against the sun's attacks.

Environmental, immunological, genetic risk factors were incriminated in the degeneration of these melanocytes in uveal melanoma [6] [7]. The role of the exposure to the sun in the development of the ocular melanoma contrary to that of the skin was not clearly established; on the other hand it was demonstrated that black skin was protective whatever the site [8]. One of the hypotheses would be that the skin and the uvea of White people, exposed to the sun would produce a factor called 'solar circulating factor' which would be responsible for the development of the intra-ocular melanoma [7]. The strong pigmentation of these structures in Black people would protect them from the production of this factor, hence the low incidence of this pathology in this race, estimated between $0.3 \%$ and $1 \%$ according to the series [8] [9]. This hypothesis seems to be strengthened by the difference of the target structures of the eye between both races. Indeed, uveal melanomas are the most frequent in White people against 3\% of the conjunctival localizations [2] [3].

On the other hand, in Black people, 50\% of the diagnosed ocular melanomas are conjunctival [10]. This is explained by the low pigmentation of the eye conjunctiva in Black people, exposing directly to ultraviolet radiations, hence this predominance of conjunctival melanoma in Black people [7]. The strong pigmentation alone does not explain this rarity of melanoma in Black people because the incidence of this cancer remains high in the other pigmented races, what enables to conclude that, the resistance of the Black with regard to melanoma would be genetic. The melanomas of the choroid can pass through the sclera through the canals of the vortex vein and develop at the level of the episclera and of the orbit as in the case of the left eye.

The rarity of bilateral cases is attested by very low incidences of $0.2 \%$ in the European and American series [5] [11]. The mechanism of the bilateralism of the ocular melanoma is unknown. It is a genetic mutation which makes conjunctiva vulnerable to the development of the ocular melanomas; or of a contralateral metastasis? Certain predispositions as the eye melanocytosis, the mutation of the p16 Cyclin-dependent kinase 4 (CDK4) gene were evoked in this bilateralism [5] [11]. We did not notice a melanocytosis in our case and the genetic tests couldn't be done. Eye metastases of a skin melanoma or those of a contralateral primitive ocular melanoma can be evoked, but they are extremely rare [5]. A complete dermatological examination did not find an evolutionary skin melanoma. The study of Singh concluded that it is rather about a lack of chance in the bilateralism of the ocular melanoma more than anything else [11]. The occurrence interval of the tumor between both eyes in our patient is in compliance with the data of the literature [5]. 
Therapeutically, the clinical researches in chemotherapy, immunotherapy or on new molecules, dedicated to this pathology, are rare, and long ago the patients were included in the available protocols for skin melanoma. Yet it is about a different disease on the genetic, biological and clinical plan. There is no reference treatment for this disease, except the local treatment. This local treatment involves proton therapy, brachytherapy, thermotherapy, evisceration and enucleation [12]. Eye morbidity due to associated complications seems to be higher in Black people with regard to White people, mostly due to delayed diagnosis because of the rarity of this affection in this race [3].

Systemic metastases of ocular melanoma, mostly hepatic, occur in 30\%-50\% of cases during development [13]. The alteration of chromosome 3 and the presence of the Protein Tyrosine kinase 2 (PTK2) gene are associated with a high risk of tumor dissemination [14]. The treatment of these metastases is mainly surgical because the chemotherapy currently available has not shown a convincing effectiveness [15].

\section{Conclusion}

Bilateral ocular melanoma in Black people is exceptional. The etiological factors and the mechanisms of bilateralism are still hypothetical. The most effective treatment is local with several methods that are not always available in Africa. Its prognosis is poor in case of metastasis due to the absence of effective chemotherapy. The only favorable prognostic factor is total carcinology exeresis.

\section{Conflict of Interest}

The authors report no conflict of interest.

\section{Patient Consent}

The patient's parent (brother) gave consent for the publication of this case; however, this case contains no personal information that could identify the patient.

\section{Ethical Approval}

Approval for the study was obtained from the national medical ethic committee.

\section{References}

[1] Singh, A.D., Bergman, L. and Seregard, S. (2005) Uveal Melanoma: Epidemiologic Aspects. Ophthalmology Clinics of North America, 18, 75-84. https://doi.org/10.1016/j.ohc.2004.07.002

[2] Zografos, L. (2002) Tumeurs pigmentées de l'uvée. In: Tumeur intraoculaire-Rapport de la société Française d'ophtalmologie. Masson, 65-279.

[3] Margo, C.E. and McLean, I.W. (1984) Malignant Melanoma of the Choroid and Ciliary Body in Black Patients. Archives of Ophthalmology, 102, 77-79. https://doi.org/10.1001/archopht.1984.01040030061035 
[4] Poso, M.Y., Mwanza, J.C. and Kayembe, D.L. (2000) Malignant Tumors of the Eye and Adnexa in Congo-Kinshasa. Journal Francais d Ophtalmologie, 23, 327-332.

[5] Bhouri, L., Lumbroso, L., Levy, C., et al. (2003) Bilateral Uveal Melanomas: Five Case Reports. Journal Francais d Ophtalmologie, 26, 149-153.

[6] Lutz, J.M., Cree, I.A. and Foss, A.J. (1999) Risk Factor for Intraocular Melanoma and Occupational Exposure. British Journal of Ophthalmology, 83, 1190-1193. https://doi.org/10.1136/bjo.83.10.1190

[7] Lee, J.A. and Merrill, J.M. (1970) Sunlight and the Aetiology of Malignant Melanoma: A Synthesis. The Medical Journal of Australia, 2, 846-851.

[8] Coleman, W.P., Gately, L.E., Krementz, A.B., Reed, R.J. and Krementz, E.T. (1980) Nevi, Lentigines and Melanomas in Blacks. Archives of Dermatology, 116, 548-551. https://doi.org/10.1001/archderm.1980.01640290058011

[9] Shields, C.L., Demirci, H., Karatza, E. and Shields, J.A. (2004) Clinical Survey of 1643 Melanocytic and Nonmelanocytic Conjunctival Tumors. Ophthalmology, 111, 1747-1754. https://doi.org/10.1016/j.ophtha.2004.02.013

[10] Miller, B., Abrahams, C., Cole, G.C. and Proctor, N.S. (1981) Ocular Malignant Melanoma in South African Blacks. British Journal of Ophthalmology, 65, 720-722. https://doi.org/10.1136/bjo.65.10.720

[11] Singh, A.D., Shields, C.L. and Shields, J.A. (1996) De Potter P. Bilateral Primary Uveal Melanoma. Bad Luck or Bad Genes? Ophthalmology, 103, 256-262. https://doi.org/10.1016/S0161-6420(96)30707-0

[12] Desjardins, L., Lumbroso-Le Rouic, L., Levy-Gabriel, C., et al. (2006) Combined Proton Beam Radiotherapy and Transpupillary Thermotherapy for Large Uveal Melanomas: A Randomized Study of 151 Patients. Ophthalmic Research, 38, 255-260. https://doi.org/10.1159/000094834

[13] Seregard, S. and Kock, E. (1995) Prognostic Indicators Following Enucleation for Posterior Uveal Melanoma. A Multivariate Analysis of Long-Term Survival with Minimized Loss to Follow-Up. Acta Ophthalmologica Scandinavica, 73, 340-344. https://doi.org/10.1111/j.1600-0420.1995.tb00039.x

[14] Trolet. J., Hupé, P., Huon, I., et al. (2009) Genomic Profiling and Identification of High-Risk Uveal Melanoma by Array CGH Analysis of Primary Tumors and Liver Metastases. Investigative Ophthalmology \& Visual Science, 50, 2572-2580. https://doi.org/10.1167/iovs.08-2296

[15] Mariani, P., Piperno-Neumann, S., Servois, V., et al. (2009) Surgical Management of Liver Metastases from Uveal Melanoma: 16 Years' Experience at the Institut Curie. European Journal of Surgical Oncology, 35, 1192-1197. https://doi.org/10.1016/j.ejso.2009.02.016 